Research Article

\title{
Patient Preferences for Nonvitamin K Antagonist Oral Anticoagulants in Stroke Prevention: A Multicountry Discrete Choice Experiment
}

\author{
Thomas Wilke, ${ }^{1}$ Anna-Katharina Meinecke, ${ }^{2}$ Bernhard Schaefer, ${ }^{2}$ Sandra Buchwald, \\ Daniel Eriksson, ${ }^{2}$ and Sabrina Müller $\mathbb{D}^{1}$ \\ ${ }^{1}$ Ingress-Health HWM GmbH, 23966 Wismar, Germany \\ ${ }^{2}$ Bayer AG, 13342 Berlin, Germany \\ Correspondence should be addressed to Sabrina Müller; sabrina.mueller@ingress-health.com
}

Received 6 September 2019; Accepted 21 October 2019; Published 18 December 2019

Academic Editor: Anne Knowlton

Copyright (C) 2019 Thomas Wilke et al. This is an open access article distributed under the Creative Commons Attribution License, which permits unrestricted use, distribution, and reproduction in any medium, provided the original work is properly cited.

\begin{abstract}
Purpose. The patient's perspective is becoming increasingly important in clinical and policy decisions. This study examined atrial fibrillation (AF) patient preferences for different characteristics of nonvitamin $\mathrm{K}$ antagonist oral anticoagulants (NOACs). Methods. A discrete choice experiment (DCE) addressing AF patients treated with NOACs in France, Germany, and the United Kingdom was conducted. The DCE included the following attributes: frequency of administration (once/twice daily), size of tablet/capsule (6-9 mm/20 mm), meal-related intake (intake with food required/independent), and distance to treating physician $(1 \mathrm{~km} / 10 \mathrm{~km})$. Preferences were analyzed based on a conditional logit regression model. Results. In total, 758 patients (males: $57.3 \%$; mean age: 71.4 years) with an average disease duration of 5.5 years were included (apixaban/dabigatran/edoxaban/ rivaroxaban: $34.0 \% / 14.5 \% / 6.6 \% / 44.9 \%$, respectively). Patients preferred NOAC treatment options characterized by once-daily dosing regimens $(42.8 \% ; p<0.001)$, shorter distance to treating physicians $(25.0 \% ; p<0.001)$, a small-sized tablet $(21.5 \%$; $p<0.001)$, and intake independent of food $(10.6 \% ; p<0.001)$. Conclusions. Patients primarily prefer a once-daily NOAC regimen. Individual preferences should be considered for the treatment of AF patients as this may result in improved treatment adherence and consequently better effectiveness and safety in routine clinical practice.
\end{abstract}

\section{Rationale and Background}

Atrial fibrillation (AF) is the most commonly sustained cardiac arrhythmia. It is estimated to occur in around $3 \%$ of adults aged 20 years and older, with a higher prevalence in the elderly and in patients with comorbidities such as hypertension, coronary artery disease, diabetes mellitus, and chronic kidney disease [1]. AF is an independent risk factor for stroke, heart failure, and mortality $[2,3]$ and increases the risk of stroke approximately five folds [3].

For many decades, warfarin and other vitamin $\mathrm{K}$ antagonists (VKAs) have been the mainstay of stroke prevention therapy in AF patients. In recent years, a number of non-VKA oral anticoagulants (NOACs) have been introduced to the market. In terms of efficacy and safety,
NOACs have been shown to be at least as effective and safe as VKAs for stroke prevention in patients with nonvalvular AF (NVAF) [4-9]. However, the lack of head-to-head trials of NOACs creates a challenge for physicians and patients in the choice of anticoagulation therapy.

Patient involvement and individual preferences are highlighted in treatment guidelines as important factors in the initiation of treatment and long-term management of AF patients $[1,10]$. Even though previous research has shown that $\mathrm{AF}$ patients prefer once-daily anticoagulation dosing $[11,12]$ therapy that does not require periprocedural bridging of anticoagulation and anticoagulation therapy that does not interact with food [12], here is only limited literature on patient preferences regarding different NOACs available. The objective of this study was to elucidate AF 
patients' preferences for attributes associated with NOAC therapy.

\section{Research Methods}

This was a cross-sectional study of AF patients in France, Germany, and the United Kingdom (UK). Study inclusion criteria were at least 18 years of age; diagnosis of AF; treated with an NOAC (apixaban, dabigatran, edoxaban, or rivaroxaban) for at least the past three months; and willing to be interviewed over telephone. The structured interviews were computer-assisted and conducted by trained interviewers.

We conducted a discrete choice experiment (DCE) to measure and quantify patient preferences for NOAC therapy in AF. The DCE is a well-accepted approach for patient preference measurement in health care. Choice experiments examine preferences using pairwise comparisons of holistic hypothetical alternatives instead of ranking or assessing single features only $[13,14]$. A series of evaluation tasks are presented to the respondent who needs to select one of the presented alternatives in each task. Each alternative is described by predefined attributes that vary across the different alternatives. The variation across the alternatives in the choice sets is achieved by assigning different levels to the attributes. The basic assumption of a DCE is that rational individuals will always choose the alternative with the higher level of expected utility. In this way, the degree to which each attribute (treatment characteristic) influences the choice of the patient can be examined $[15,16]$.

The study included treatment characteristics identified in the literature as influencing anticoagulation therapy preferences [12] and NOAC-related factors identified in the European summaries of product characteristics for each respective anticoagulant [17-20]. Due to the lack of head-tohead randomized trials of NOACs, there is no clinical evidence of differences between the medications in terms of efficacy and safety. Consequently, these attributes were not included in the study. In addition, a comparator attribute defined as distance to the treating physician was included as a way to express the marginal valuations of the treatment attributes in terms of an easily understood unit (distance in kilometer $(\mathrm{km})$ ). Table 1 provides a summary of the included attributes and their levels as used in the DCE.

A fractional factorial design was generated using IBM SPSS Statistic software ( $v$ 20) [21, 22]. Based on an orthogonal main-effects design, a set of eight different choice sets, each with two alternative treatment options was derived. A ninth choice set was integrated to assess consistency of response behavior. This test set duplicated a previous decision situation with interchanged treatment options. All choice sets were graphically visualized to facilitate comprehension of the different attributes and their levels (see Supplementary Figure 1 for an example choice set used in the study).

Baseline patient characteristics were analyzed using descriptive statistics. Categorical data were reported as proportions and continuous data as mean, standard deviation, and median. Patients with inconsistent DCE data were excluded from the analyses. Inconsistency was assessed based on responses on the abovementioned test set. The DCE dataset was analyzed using a conditional logit regression model that included all attributes (NOAC treatment characteristics) as independent variables. The conditional logit relates the probability of choice among the alternatives (choice sets) to the characteristics of the attribute levels defining those alternatives [15]. The relative importance of the NOAC treatment attributes was estimated for the overall sample and for prespecified subgroups.

\section{Main Results}

A total of 898 patients completed the study. Of these, 140 (16\%) were excluded due to inconsistency in their responses, resulting in a study population of 758 patients (Germany: 280 (37\%); France: 338 (45\%); UK: 140 (18\%)). Median age was 72 years, and $43 \%$ were female. On average, patients had been diagnosed with AF more than 5 years ago and been on treatment with their current NOAC for 2 years. Overall, $34 \%$ of patients were treated with apixaban, $14 \%$ with dabigatran, $7 \%$ with edoxaban, and $45 \%$ with rivaroxaban. A comprehensive list of baseline characteristics is provided in Table 2. As also shown in Table 2, patients who were excluded due to inconsistent response behavior were significantly older, but were otherwise similar to the study population in terms of demographic and clinical characteristics.

Table 3 shows the results of the conditional logistic regression analyses. A once-daily dosing regime was strongly preferred in comparison with twice-daily dosing (utility: $0.80 ; p<0.001)$. Patients also expressed preference for a tablet sized $6-9 \mathrm{~mm}$ rather than a $20 \mathrm{~mm}$ capsule (utility: $0.40 ; p<0.001)$ and a medication that does not need to be taken with food (utility: $0.20 ; p<0.001$ ). Patients also favored a shorter distance to the treating physician (utility: $0.47 ; p<0.001)$.

The marginal valuations of the treatment attributes (expressed as distance willing to travel for an improvement in a positively valued attribute) are presented in Table 3 as well as in Figure 1. On average, patients were willing to travel an additional $27 \mathrm{~km}$ to their treating physician in order to receive an NOAC that combines all the preferred attribute levels (once-daily dosing, small tablet size, and a medication that does not need to be taken with food). For a treatment option that provides at least a once-daily dosing (instead of twice-daily), patients were willing to accept a longer distance of $15.4 \mathrm{~km}$. The equivalent distances for receiving a smaller tablet and a medication that can be taken with or without food were $7.7 \mathrm{~km}$ and $3.8 \mathrm{~km}$, respectively.

An overview of the relative impact of each of the four attributes stratified by patient characteristics is provided in Supplementary Figure 2. Preferences were generally similar across subgroups with once-daily dosing frequency valued the highest.

\section{Discussion}

Our study adds new evidence on patient preferences for NOACs. The results of our study illustrate that patients 
Table 1: Attributes and levels used in the discrete choice experiment.

\begin{tabular}{|c|c|c|}
\hline Attribute & Level 1 & Level 2 \\
\hline Frequency of administration & Once daily & Twice daily \\
\hline Size of tablet/capsule & 6-9 $\mathrm{mm}$ tablet & $20 \mathrm{~mm}$ capsule \\
\hline Meal-related intake & Intake with food required & Intake independent of food \\
\hline Distance to treating physician & $1 \mathrm{~km}$ & $10 \mathrm{~km}$ \\
\hline
\end{tabular}

TABle 2: Patient characteristics.

\begin{tabular}{|c|c|c|c|}
\hline \multicolumn{2}{|l|}{ Variable } & Patients included & Patients excluded due to inconsistent DCE data \\
\hline \multicolumn{2}{|l|}{$N$} & 758 & 140 \\
\hline \multicolumn{2}{|c|}{ Age in years, median, mean (SD) } & $72,71.4(9.9)$ & $77,74.4(10.0)^{*}$ \\
\hline \multicolumn{2}{|c|}{ Female gender, $n(\%)$} & $324(42.7)$ & $60(42.9)$ \\
\hline \multicolumn{4}{|c|}{ BMI, median, mean (SD) } \\
\hline \multicolumn{2}{|c|}{ Male } & $27,28.1(4.7)$ & $27,27.8(5.8)$ \\
\hline \multicolumn{2}{|l|}{ Female } & $26,27.5(5.6)$ & $26,26.5(5.5)$ \\
\hline \multicolumn{4}{|l|}{ Country, $n(\%)$} \\
\hline \multicolumn{2}{|l|}{ Germany } & $280(36.9)$ & $42(30.0)$ \\
\hline \multicolumn{2}{|l|}{ France } & $338(44.6)$ & $62(44.3)$ \\
\hline \multicolumn{2}{|c|}{ UK } & $140(18.5)$ & $36(25.7)$ \\
\hline \multicolumn{2}{|c|}{ AF duration in years, median, mean (SD) } & $3,5.5(6.4)$ & $4,5.7(6.1)$ \\
\hline \multicolumn{2}{|c|}{$\begin{array}{l}\text { Duration of current NOAC treatment in } \\
\text { years, median, mean (SD) }\end{array}$} & $2,2.1(1.7)$ & $2,2.4(2.0)$ \\
\hline \multicolumn{4}{|c|}{ Current anticoagulant, $n(\%)$} \\
\hline \multirow{2}{*}{ Apixaban } & $2.5 \mathrm{mg}$ & $73(9.6)$ & $17(12.1)$ \\
\hline & $5 \mathrm{mg}$ & $185(24.4)$ & $32(22.9)$ \\
\hline \multirow{2}{*}{ Edoxaban } & $30 \mathrm{mg}$ & $11(1.5)$ & $1(0.7)$ \\
\hline & $60 \mathrm{mg}$ & $39(5.2)$ & $4(2.9)$ \\
\hline \multirow{2}{*}{ Dabigatran } & $110 \mathrm{mg}$ & $50(6.6)$ & $8(5.7)$ \\
\hline & $150 \mathrm{mg}$ & $60(7.9)$ & $8(5.7)$ \\
\hline \multirow{2}{*}{ Rivaroxaban } & $15 \mathrm{mg}$ & $97(12.8)$ & $21(15.0)$ \\
\hline & $20 \mathrm{mg}$ & $243(32.1)$ & $49(35.0)$ \\
\hline \multicolumn{4}{|c|}{ Frequency of administration, $n(\%)$} \\
\hline \multirow{2}{*}{ Apixaban } & Once daily & $2(0.3)$ & $0(0.0)$ \\
\hline & Twice daily & $256(33.8)$ & $49(35.0)$ \\
\hline \multirow{2}{*}{ Edoxaban } & Once daily & $50(6.6)$ & $5(3.6)$ \\
\hline & Twice daily & $0(0.0)$ & $0(0.0)$ \\
\hline \multirow{2}{*}{ Dabigatran } & Once daily & $2(0.3)$ & $0(0.0)$ \\
\hline & Twice daily & $108(14.2)$ & $16(11.4)$ \\
\hline \multirow{2}{*}{ Rivaroxaban } & Once daily & $340(44.9)$ & $70(50.0)$ \\
\hline & Once daily & $0(0.0)$ & $0(0.0)$ \\
\hline \multicolumn{2}{|c|}{$\begin{array}{l}\text { Patients previously prescribed with OAC, } \\
n(\%)\end{array}$} & $50(6.6)$ & $9(6.4)$ \\
\hline \multicolumn{2}{|c|}{$\begin{array}{l}\text { Currently taking other prescription } \\
\text { medications regularly, } n(\%)\end{array}$} & $720(95.0)$ & $134(95.7)$ \\
\hline $\begin{array}{l}\text { Number of d } \\
\text { median, mean }\end{array}$ & lications, & $3,4.0(2.9)$ & $4,4.6(2.9)$ \\
\hline Comorbidities, & & & \\
\hline Heart failure & & $224(32.2)$ & $53(37.9)$ \\
\hline Hypertension & & $472(62.3)$ & $75(53.6)$ \\
\hline Diabetes & & $166(21.9)$ & $31(22.1)$ \\
\hline Stroke & & $75(9.9)$ & $20(14.3)$ \\
\hline Impaired kid & & $65(8.6)$ & $15(10.7)$ \\
\hline Vascular dise & & $95(12.5)$ & $23(16.4)$ \\
\hline Type of primari & hysician, $n$ & & \\
\hline GP & & $220(29.0)$ & $51(36.4)$ \\
\hline Cardiologist & & $627(82.7)$ & $110(78.6)$ \\
\hline Others & & $27(3.6)$ & $2(1.4)$ \\
\hline
\end{tabular}

*statistically significant at $p<0.05$. 
TABLE 3: Results of the conditional logit model.

\begin{tabular}{|c|c|c|c|c|c|}
\hline \multirow[b]{2}{*}{ Attribute } & \multicolumn{5}{|c|}{ Full model (fixed effect) } \\
\hline & Levels & Coefficient & $p$ value & $95 \% \mathrm{CI}$ & $\begin{array}{l}\text { Marginal distance*, } \\
\mathrm{km}[95 \% \mathrm{CI}]\end{array}$ \\
\hline Frequency of administration & $\begin{array}{l}\text { Once daily } \\
\text { Twice daily (reference) }\end{array}$ & 0.795 & $<0.001$ & {$[0.738-0.853]$} & 15.4 [14.3-16.5] \\
\hline Size of tablet/capsule & $\begin{array}{c}\text { Tablet 6-9 mm } \\
\text { Capsule } 20 \mathrm{~mm} \text { (reference) }\end{array}$ & $\begin{array}{c}0.400 \\
0\end{array}$ & $<0.001$ & {$[0.343-0.456]$} & $7.7[6.6-8.8]$ \\
\hline Meal-related intake & $\begin{array}{l}\text { Intake independent of food } \\
\text { Intake with food required (reference) }\end{array}$ & $\begin{array}{c}0.198 \\
0\end{array}$ & $<0.001$ & {$[0.142-0.254]$} & $3.8[2.7-4.9]$ \\
\hline Distance to treating physician & $\begin{array}{c}1 \mathrm{~km} \\
10 \mathrm{~km}(\text { ref. })\end{array}$ & $\begin{array}{c}0.465 \\
0\end{array}$ & $<0.001$ & {$[0.408-0.522]$} & $\mathrm{n} / \mathrm{a}$ \\
\hline
\end{tabular}

* The marginal estimate of the distance that an average patient is willing to travel to the treating physician in order to obtain the specified attribute level compared with the reference level.

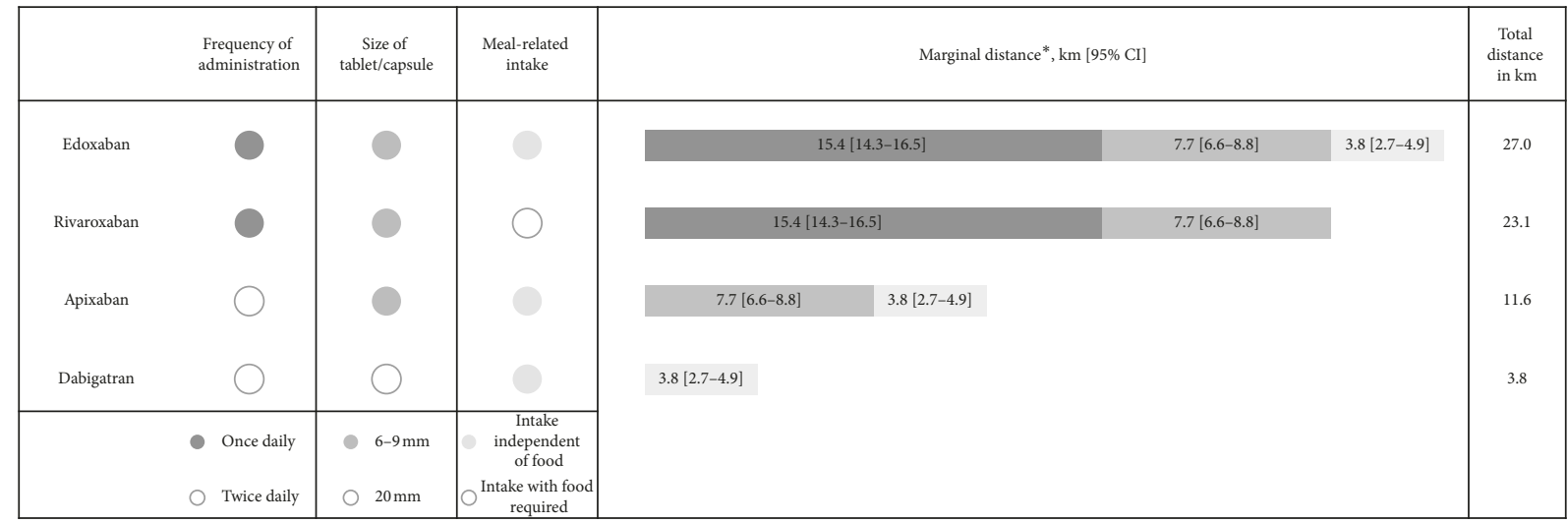

FIgURE 1: Derived willingness to accept additional distance to the treating physician for different available NOACs.

prefer an NOAC regimen consisting of a single daily dose. Frequency of administration was the most important attribute (42.8\% impact on the overall decision of patients), followed by distance to treating physician (25.0\%) and size of the tablet/capsule (21.5\%). The least important attribute was meal-related intake (10.6\%).

One of the advantages of the DCE methodology is that properties of specific treatments (attribute levels) can be transferred into utilities that in turn describe trade-off patients make in deciding between treatment options. Compared with the (theoretically) least preferred NOAC treatment option, the highest utility (expressed as accepted distance to the treating physician) was observed for the once-daily treatment options edoxaban $(27 \mathrm{~km})$ and rivaroxaban $(23.1 \mathrm{~km})$, followed by apixaban $(11.6 \mathrm{~km})$ and dabigatran $(3.8 \mathrm{~km})$ as the least preferred NOAC treatment options. Our findings were generally consistent across subgroups of patients with a once-daily dosing frequency preferred over twice-daily administration. While still ranking once-daily dosing as the most important attribute, the elderly and women seemed to put more relative value on having a shorter distance to their treating physicians compared with the general AF population. Furthermore, relative to the study population, patients in France seemed to value a treatment that can be taken independently of food, while this attribute was of minimal importance to patients in the UK. Based on analyses by treatment, the data seemed to indicate a level of adaption by patients to the current NOAC regimen, which may be explained by the development routines for taking medications long-term [23]. For example, patients receiving apixaban, dabigatran, or rivaroxaban seemed to rank attributes specific to these treatments relatively low (dosing frequency, capsule size, and mealrelated intake, respectively; see Supplementary Figure 2).

Our findings are consistent with previous preference studies. In a European survey of 1,507 patients with AF, $80.7 \%$ of patients expressed a preference for taking anticoagulation medication once daily compared with only $7.6 \%$ who preferred a twice-daily regimen [11]. Twice-daily dosing frequency was also identified as a barrier to treatment adherence in an Italian study of 525 patients treated with VKAs who were assessed for switching to NOACs [24]. In another preference study conducted in Germany, Switzerland, and Sweden using a DCE approach, frequency of administration also prevailed as the most important treatment attribute among other regimen-related characteristics comparing VKAs and NOACs [25].

We acknowledge some limitations of our study. Selection bias arising from differences in patient characteristics between those willing to participate in the study and those who declined to participate cannot be ruled out. The information presented to patients in the DCE is a 
simplification of reality, and it is possible that unobserved attributes influenced the decisions of patients. While the DCE can be perceived as a complex approach for both interviewers and patients, the interviewers in our study were intensively trained and supported by a guideline on how to design a hypothetical atmosphere within the experiment. Furthermore, the choice situations were visualized and made available to participants.

\section{Conclusions}

This study showed that patients primarily prefer a once-daily NOAC regimen. Individual preferences should be considered for the initiation and long-term treatment of AF patients as this may result in improved treatment adherence and consequently better effectiveness and safety in routine clinical practice.

\section{Data Availability}

The data supporting the findings of this study are available from the corresponding author (SM) upon reasonable request.

\section{Additional Points}

Key Points. (i) This cross-sectional observational study assessed NOAC treatment preferences of AF patients in France, Germany, and the United Kingdom, using a discrete choice experiment framework; (ii) patients preferred NOAC regimens with once-daily dosing frequency and tablets/ capsules of smaller size; (iii) patients were willing to accept a significant burden in order to receive their preferred NOAC treatment; they were willing to travel an additional $27 \mathrm{~km}$ to their treating physician in order to receive a NOAC with all the preferred attributes

\section{Ethical Approval}

All procedures of the conducted survey were in accordance with the legal and ethical guidelines laid out by EphMRA/ BHBIA. This study was a noninterventional, patient survey with an anonymized collection of patient reports and without collection of clinical information by the treating physicians. This article does not contain any studies with animals performed by any of the authors.

\section{Consent}

Informed consent was obtained from all individual participants included in the study.

\section{Disclosure}

Findings from this study were previously presented as a poster at the ESC Congress 2018 (https://academic.oup.com/ eurheartj/article/39/suppl_1/ehy564.P611/5082056).

\section{Conflicts of Interest}

Sabrina Müller is an employee of Ingress-health; Ingresshealth received funding from Bayer to support the conceptual design of study and to conduct the analysis of the study data. Thomas Wilke has received honoraria from several pharmaceutical/consultancy companies, e.g., Novo Nordisk, AbbVie; Merck; GSK, BMS, AstraZeneca, Bayer, Boehringer Ingelheim, and Pharmerit. Anna-Katharina Meinecke, Bernhard Schaefer, Sandra Buchwald, and Daniel Eriksson are employees of Bayer AG.

\section{Acknowledgments}

Blueprint Partnership Ltd, Lisa Heideman, was responsible for data collection throughout the study. This study was funded by Bayer AG.

\section{Supplementary Materials}

Supplementary Figure 1: example of a visualized DCE set. Supplementary Figure 2: relative importance of NOAC treatment attributes. (Supplementary Materials)

\section{References}

[1] P. Kirchhof, S. Benussi, D. Kotecha et al., "2016 ESC Guidelines for the management of atrial fibrillation developed in collaboration with EACTS," European Journal of CardioThoracic Surgery, vol. 50, pp. e1-e88, 2016.

[2] E. J. Benjamin, P. A. Wolf, R. B. D’Agostino, H. Silbershatz, W. B. Kannel, and D. Levy, "Impact of atrial fibrillation on the risk of death," Circulation, vol. 98, no. 10, pp. 946-952, 1998.

[3] P. A. Wolf, R. D. Abbott, and W. B. Kannel, "Atrial fibrillation as an independent risk factor for stroke: the Framingham Study," Stroke, vol. 22, no. 8, pp. 983-988, 1991.

[4] S. J. Connolly, M. D. Ezekowitz, S. Yusuf et al., "Dabigatran versus warfarin in patients with atrial fibrillation," New England Journal of Medicine, vol. 361, no. 12, pp. 1139-1151, 2009.

[5] C. T. Ruff, R. P. Giugliano, E. M. Antman et al., "Evaluation of the novel factor Xa inhibitor edoxaban compared with warfarin in patients with atrial fibrillation: design and rationale for the Effective aNticoaGulation with factor xA next GEneration in atrial fibrillation-thrombolysis in myocardial infarction study 48 (ENGAGE AF-TIMI 48)," American Heart Journal, vol. 160, no. 4, pp. 635-641, 2010.

[6] K. A. A. Fox, J. P. Piccini, D. Wojdyla et al., "Prevention of stroke and systemic embolism with rivaroxaban compared with warfarin in patients with non-valvular atrial fibrillation and moderate renal impairment," European Heart Journal, vol. 32, no. 19, pp. 2387-2394, 2011.

[7] S. J. Connolly, J. Eikelboom, C. Joyner et al., "Apixaban in patients with atrial fibrillation," New England Journal of Medicine, vol. 364, no. 9, pp. 806-817, 2011.

[8] C. T. Ruff, R. P. Giugliano, E. Braunwald et al., "Comparison of the efficacy and safety of new oral anticoagulants with warfarin in patients with atrial fibrillation: a meta-analysis of randomised trials," The Lancet, vol. 383, no. 9921, pp. 955-962, 2014.

[9] I. Savelieva and A. J. Camm, "Practical considerations for using novel oral anticoagulants in patients with atrial fibrillation," Clinical Cardiology, vol. 37, no. 1, pp. 32-47, 2014. 
[10] J. Steffel, P. Verhamme, T. S. Potpara et al., "The 2018 European Heart Rhythm Association Practical Guide on the use of non-vitamin $\mathrm{K}$ antagonist oral anticoagulants in patients with atrial fibrillation," European Heart Journal, vol. 39, no. 16, pp. 1330-1393, 2018.

[11] A. Bakhai, A. Sandberg, T. Mittendorf et al., "Patient perspective on the management of atrial fibrillation in five European countries," BMC Cardiovascular Disorders, vol. 13, p. 108, 2013.

[12] B. Böttger, I.-M. Thate-Waschke, R. Bauersachs, T. Kohlmann, and T. Wilke, "Preferences for anticoagulation therapy in atrial fibrillation: the patients' view," Journal of Thrombosis and Thrombolysis, vol. 40, no. 4, pp. 406-415, 2015.

[13] M. D. Clark, D. Determann, S. Petrou, D. Moro, and E. W. de Bekker-Grob, "Discrete choice experiments in health economics: a review of the literature," PharmacoEconomics, vol. 32, no. 9, pp. 883-902, 2014.

[14] E. W. d. Bekker-Grob, M. Ryan, and K. Gerard, "Discrete choice experiments in health economics: a review of the literature," Health Economics, vol. 21, no. 2, pp. 145-172, 2012.

[15] A. B. Hauber, J. M. González, C. G. M. Groothuis-Oudshoorn et al., "Statistical methods for the analysis of discrete choice experiments: a report of the ISPOR conjoint analysis good research practices task force," Value in Health, vol. 19, no. 4, pp. 300-315, 2016.

[16] J. J. Louviere, T. N. Flynn, and R. T. Carson, "Discrete choice experiments are not conjoint analysis," Journal of Choice Modelling, vol. 3, no. 3, pp. 57-72, 2010.

[17] Pradaxa, "EPAR—product information: 06/06/2018 Pradaxa," EMEA/H/C/000829-II/0108, Boehringer Ingelheim International $\mathrm{GmbH}$, Ingelheim am Rhein, Germany, 2018, https://www.ema.europa.eu/en/documents/productinformation/pradaxa-epar-product-information_en.pdf.

[18] Eliquis, "EPAR-product information: 03/08/2018 eliquis," EMEA/H/C/002148-IAIN/0056, Bristol-Myers Squibb, Dublin, Ireland, 2018, https://www.ema.europa.eu/en/documents/ product-information/eliquis-epar-product-information_en.pdf.

[19] Lixiana, "EPAR-product information: 02/08/2018 lixiana," EMEA/H/C/002629-IAIN/0018, Daiichi Sankyo Europe GmbH, Munich, Germany, 2018, https://www.ema.europa.eu/en/ documents/product-information/lixiana-epar-productinformation_en.pdf.

[20] Xarelto, "EPAR-Product Information: 01/07/2018 Xarelto," EMEA/H/C/000944-P46/42, Bayer, Leverkusen, Germany, 2018, https://www.ema.europa.eu/en/documents/productinformation/xarelto-epar-product-information_en.pdf.

[21] J. J. Louviere, D. A. Hensher, J. Swait, and W. L. Adamowicz, Stated Choice Methods: Analysis and Applications, Cambridge University Press, Cambridge, UK, 7th edition, 2010.

[22] J. Bennett and R. K. Blamey, The Choice Modelling Approach to Environmental Valuation, Edward Elgar, Cheltenham, UK, 2001.

[23] ̊. Audulv, T. Packer, S. Hutchinson, K. S. Roger, and G. Kephart, "Coping, adapting or self-managing-what is the difference? A concept review based on the neurological literature," Journal of Advanced Nursing, vol. 72, no. 11, pp. 2629-2643, 2016.

[24] D. Barcellona, M. Luzza, N. Battino, L. Fenu, and F. Marongiu, "The criteria of the Italian Federation of Thrombosis Centres on DOACs: a "real world" application in nonvalvular atrial fibrillation patients already on Vitamin $\mathrm{K}$ Antagonist," Internal and Emergency Medicine, vol. 10, no. 2, pp. 157-163, 2015.
[25] T. Wilke, S. Mueller, S. Bloempott, M. Rimle, B. Amann-Vesti, and S. Schäfer, "Präferenzen von patienten mit vorhofflimmern bezüglich der therapieeigenschaften von oralen antikoagulanzien: ein discrete-choice-experiment in der schweiz," Ars Medici, vol. 108, pp. 605-606, 2018. 


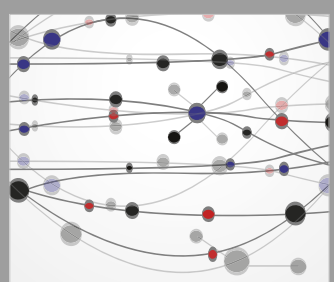

The Scientific World Journal
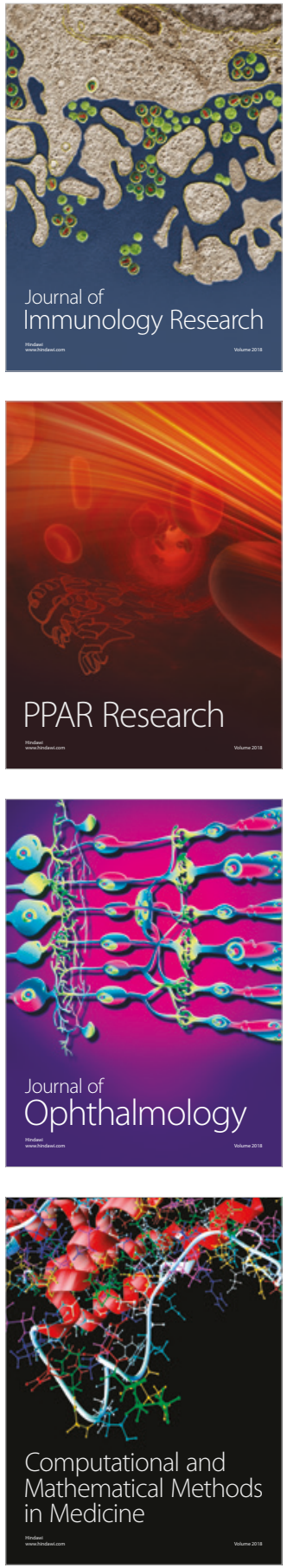

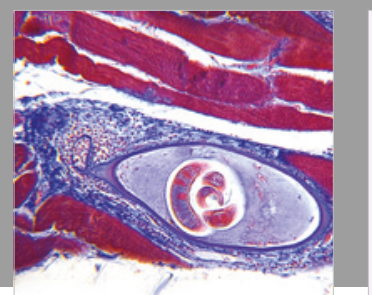

Gastroenterology Research and Practice

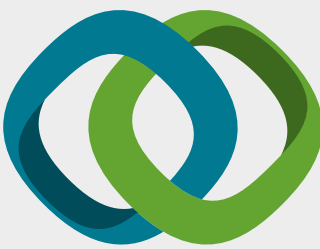

\section{Hindawi}

Submit your manuscripts at

www.hindawi.com
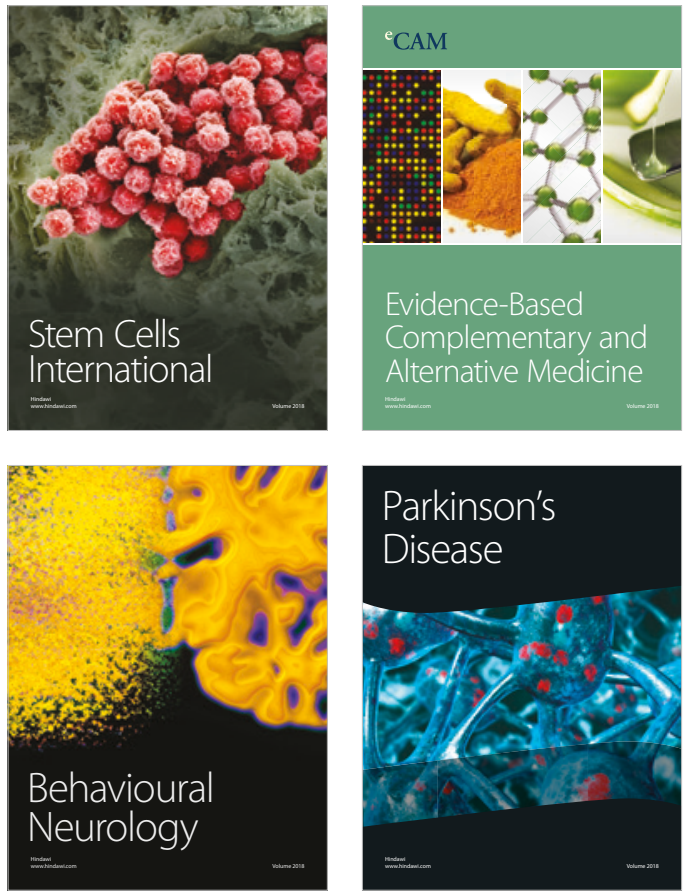

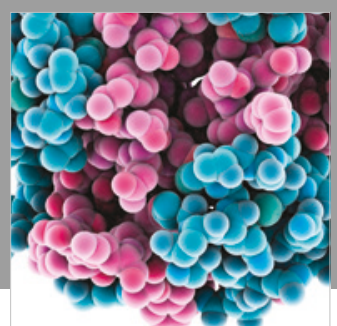

ournal of

Diabetes Research

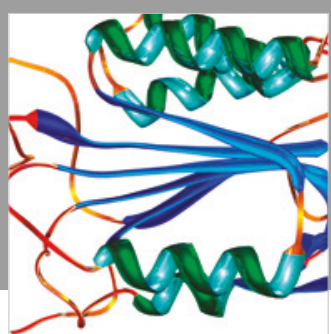

Disease Markers
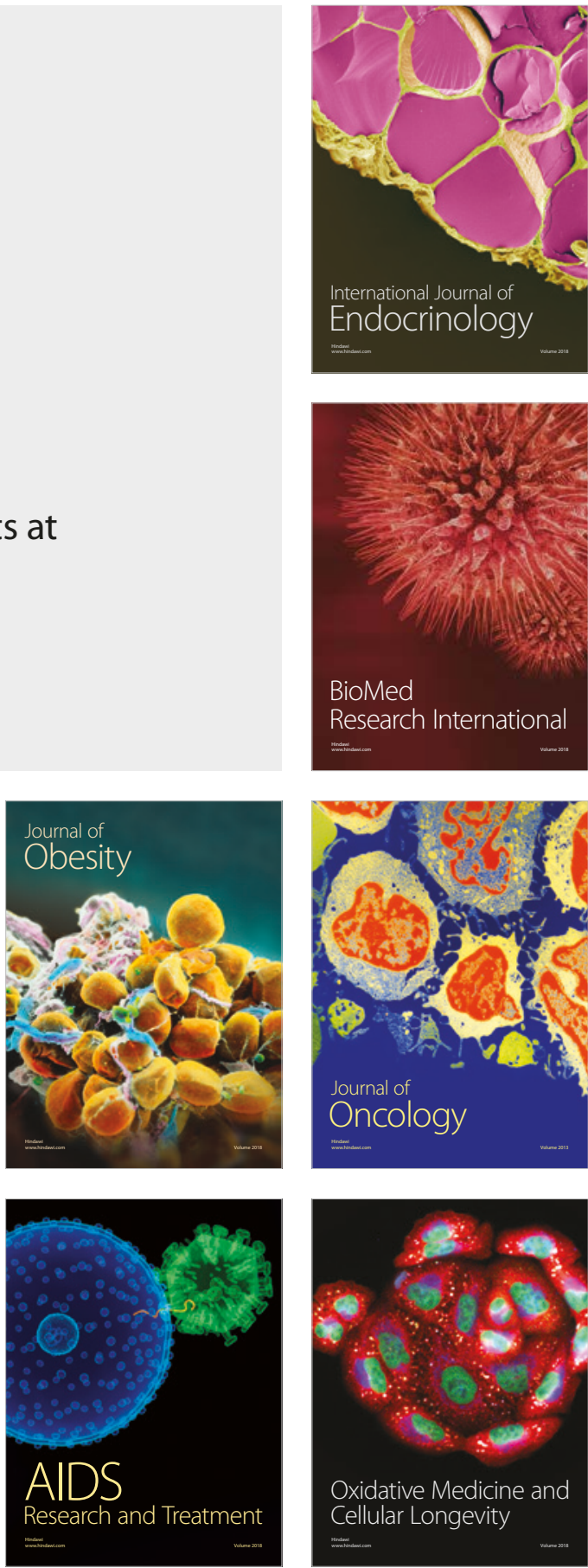